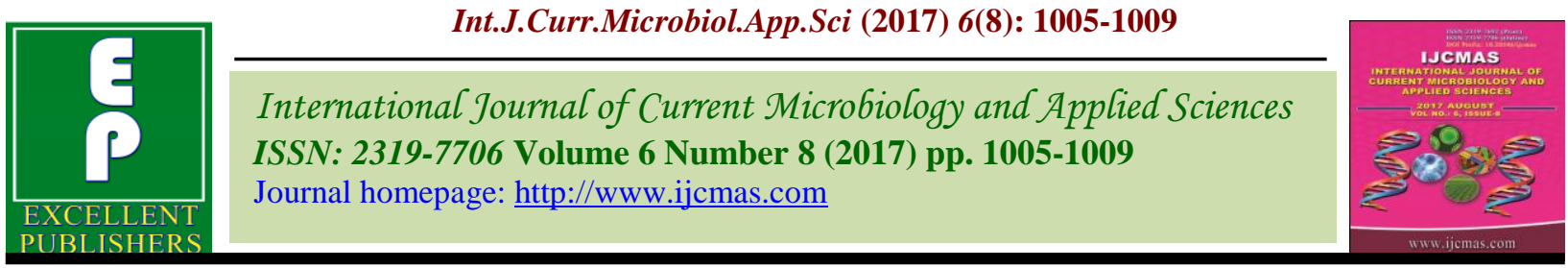

Original Research Article

https://doi.org/10.20546/ijcmas.2017.608.124

\title{
Yield Forecast of Rice Crop in Eastern U.P. Using Simulation Model
}

\author{
Ashish Singh, A.K. Singh, A.N. Mishra and C.B.Singh ${ }^{*}$ \\ Department of Agricultural Meteorology, N D University of Agriculture and Technology \\ Narendra Nagar, Kumarganj, Faizabad-224229 (U.P), India \\ *Corresponding author
}

A B S T R A C T

Keywords

Yield, Prediction,

Model,

calibration,

Validation,

DSSAT.

Article Info

Accepted:

14 June 2017

Available Online:

10 August 2017
An experiment was conducted during kharif 2015 and 2016 at Agro met Research Farm of NDUAT as to basis the yield forecast Yield Forecast of rice crop in Eastern U.P. using simulation Model. The genetic coefficients were determined by the Decision Support System for Agro Technology Transfer (DSSAT) model using the identical management and other conditions as in the field experiment for three varieties of rice (Sarooj-52, NDR-359 and Swarna). These determined coefficients were used in the subsequent in calibration on validation and other applications. Results reveal that observed value of grain yield of rice in July $5^{\text {th }}$ transplanted rice was higher over simulated value, due to higher number of days taken to anthesis and physiological maturity over simulated value. Due to delay in transplanting, the grain yield of rice decreased in accordance with observed value too. This shows the better sensitivity of DSSAT model.

\section{Introduction}

An Agricultural model contains many simple, empirically derived relation-ships that do not completely represent actual plant processes. When models are adequately tested against observed data (calibration and validation process), the results represent agricultural output under current climate conditions. The agricultural models simulate the current range of agricultural technologies available worldwide.

They do not include potential improvements in such technology, but can be used to test the effects of some potential improvements, such as improved varieties and irrigation schedules. A range of agricultural models are used widely by scientists, technical extension services, commercial farmers and resource managers to evaluate agricultural alternatives in a given location under different conditions. Decision Support System for Agro Technology Transfer (DSSAT) includes a basic set of tools for the preparation of the input data, as well as application programmes for seasonal, crop rotation and spatial analysis. (Anonymous, 2007 and Aggarwal et al., 1997) In simulation of systems, carbon from canopy assimilation forms the essential core of most simulations that deal with the growth of vegetation. Change in weather to 
warm and humid may lead to the more rapid development of a plant disease, a loss in yield of a crop and consequent financial adversity for individual farmers and so for the people of a region. Most natural systems are complex. Many do not have boundaries. The bio-system is comprised of a complex interaction among the soil, the atmosphere and the plants that live in it. A change or alteration of one element may yield both desirable and undesirable consequences. (Anonymous, 2013) Minimizing the undesirable, while reaching the desired end result is the principle aim of the agro meteorologists. In any constructive study related to agricultural meteorology, the use of mathematical modeling is essential. Of the different modeling techniques, mathematical modeling enables one to predict the behavior of design while keeping the expense at a minimum. Agricultural systems are basically modified ecosystems. Managing these systems is very difficult. These systems are influenced by the weather both in length and breadth. So, these have to be managed through models which are possible only through classical engineering expertise (Murthy, 2002). Computer models, in general, are a mathematical representation of a real world system. One of the main goals of crop simulation models is to estimate agricultural production as a function of weather and soil conditions as well as crop management. These models use one or more sets of differential equations and calculated both rate and state variables over time, normally from planting to maturity or final harvest. Hence present investigation was undertaken.

\section{Materials and Methods}

Collection of daily historical weather data of last 20 years, crop data and soil data were made. Minimum data set for Rice crop of last three years was required for operation and evaluation of simulation model. Calibration of model was made with the historical data of kharif rice 2013 and 2014. Validation of the model was done with the experimental data of rice 2015 and 2016. Genetic coefficient of the varieties tested under different growing environment was determined. Comparison of simulated value with observed value was made for phenological stages of crop and grain yield under different growing environment of cultivars tested. Observed data on growth, yield and yield components of different rice cultivars at different dates of transplanting under investigation for Rice 2015 and 2016 were taken for simulation of modeling. These data were used to test and validate the model.

\section{Results and Discussion}

The genetic coefficients were determined by the Decision Support System for Agro Technology Transfer (DSSAT) model using the identical management and other conditions as in the field experiment for three varieties of rice and has been presented in table 1 . These coefficients were used in the subsequent calibration and validation and other applications using DSSAT model version. (Bemal et al., 2009 and Tripathi, et al., 1999) 4.5 for rice PI, Flowering, maturity and yield prediction were made under three date of sowing.

The predicted values were to be closed to observed values (Fig. 1). Higher days taken to different phenophases were recorded in timely transplanted rice of $5^{\text {th }}$ July.

\section{Validation}

Validation of the model was done with the experimental data of rice 2015 and 2016. Observed value of grain yield of rice in July $5^{\text {th }}$ transplanted rice was higher over simulated value (Table 2). Days taken to anthesis and physiological maturity and grain 
yield were higher in $5^{\text {th }}$ July transplanting which were decreased with subsequent delay in transplanting during both the years of investigation. This may be due to higher number of days taken to anthesis and physiological maturity over simulated value (Boote et al., 2008). Due to delay in transplanting, the grain yield of rice decreased in accordance with observed value which shows the better sensitivity of DSSAT model.

Table.1 Genetic coefficient of different rice varieties

\begin{tabular}{|c|c|c|c|c|c|c|c|c|c|c|}
\hline VAR\# & $\begin{array}{l}\text { VAR- } \\
\text { Name }\end{array}$ & ECO\# & $\mathbf{P}_{1}$ & $\mathbf{P}_{2} \mathbf{R}$ & $\mathbf{P}_{5}$ & $\mathbf{P}_{2} \mathrm{O}$ & $\mathbf{G}_{1}$ & $\mathbf{G}_{2}$ & $\mathbf{G}_{3}$ & $\mathbf{G}_{4}$ \\
\hline IB0201 & $\begin{array}{l}\text { NDR- } \\
\text { 359 }\end{array}$ & IB0001 & 850 & 180 & 180 & 10.9 & 34.5 & .0280 & 1 & 0.90 \\
\hline IB0202 & $\begin{array}{l}\text { Sarooj- } \\
52\end{array}$ & IB0001 & 955 & 160 & 200 & 10.5 & 39 & .0290 & 1 & 0.85 \\
\hline IB0203 & Swarna & IB0001 & 1100 & 190 & 260 & 10.2 & 48 & .0300 & 1 & 0.85 \\
\hline
\end{tabular}

Table.2 Comparison between simulated and observed values of rice

\begin{tabular}{|l|c|c|c|c|c|c|}
\hline \multicolumn{7}{|c|}{ 2014 } \\
\hline \multicolumn{2}{|c|}{ 5 July } & \multicolumn{2}{c|}{ 15 July } & \multicolumn{2}{c|}{ 25 July } \\
\hline Parameters & SIM & OBS & SIM & OBS & SIM & OBS \\
\hline Anth. day & 91 & 90 & 91 & 87 & 90 & 85 \\
\hline Phy. Maty. & 116 & 123 & 116 & 114 & 116 & 109 \\
\hline Grain yield & 4122 & 4168 & 4160 & 3964 & 4249 & 3782 \\
\hline
\end{tabular}

\begin{tabular}{|c|c|c|c|c|c|c|}
\hline \multicolumn{7}{|c|}{2015} \\
\hline \multicolumn{3}{|c|}{5 July } & \multicolumn{2}{|c|}{15 July } & \multicolumn{2}{|c|}{25 July } \\
\hline Parameters & SIM & OBS & SIM & OBS & SIM & OBS \\
\hline Anth. day & 92 & 93 & 92 & 90 & 90 & 85 \\
\hline Phy. Maty. & 117 & 128 & 118 & 120 & 117 & 114 \\
\hline Grain yield & 4780 & 4132 & 4691 & 3731 & 4546 & 3615 \\
\hline
\end{tabular}

\begin{tabular}{|l|c|c|c|c|c|c|}
\hline \multicolumn{9}{|c|}{2016} \\
\hline \multicolumn{3}{|c|}{ 5 July } & \multicolumn{2}{c|}{ 15 July } & \multicolumn{2}{c|}{ 25 July } \\
\hline Parameters & SIM & OBS & SIM & OBS & SIM & OBS \\
\hline Anth. day & 89 & 93 & 90 & 90 & 90 & 88 \\
\hline Phy. Maty. & 114 & 133 & 116 & 124 & 116 & 118 \\
\hline Grain yield & 4178 & 4224 & 4326 & 3979 & 4178 & 3952 \\
\hline
\end{tabular}


Fig.1 Prediction of PI, flowering, maturity and rice yield
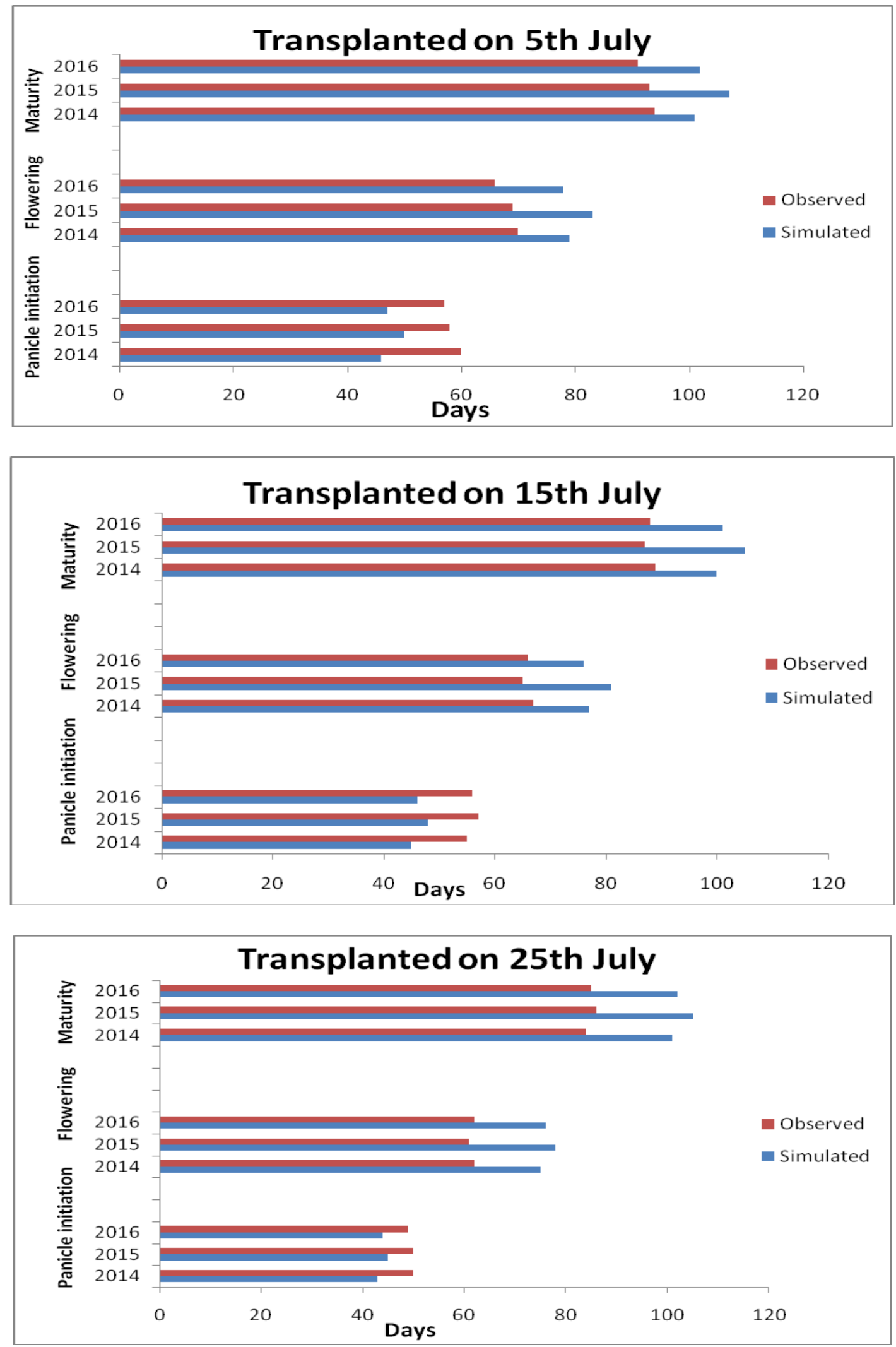
In conclusion, the genetic coefficients determined were used in the calibration and validation and other applications using DSSAT model version 4.5 for rice. Panicle initiation, Flowering, maturity and yield prediction were made. The predicted values were closed to observed values. Higher days taken to different phenophases were recorded in timely transplanted rice of $5^{\text {th }}$ July. Observed value of grain yield of rice in July $5^{\text {th }}$ transplanted rice was higher over simulated value. Days taken to anthesis and physiological maturity and grain yield were higher in $5^{\text {th }}$ July transplanting which were decreased with subsequent delay in transplanting. Due to delay in transplanting, the grain yield of rice decreased in accordance with observed value. Which shows the better sensitivity of DSSAT model.

\section{References}

Anonymous (2007) Annual Progress Report of Impact Adaptation and Vulnerability of Indian Agriculture to climate change. Dept. of Agri. Met. NDUAT, Faizabad (U.P).

Anonymous (2013) Annual Progress Report of AICRP on Agrometeorology, CRIDA Hyderabad.

Bemal, S.S., Singh, D. and Singh, S. (2009). Seasonal climatic variability impact on rice productivity in Haryana. Journal of Agrometeorology, 11 (special issue):6465.

Boote, K. J., Jones, J. W. and Hoogenboom, G. (2008). Crop simulation models as tools for Agro-advisories for weather and disease effects on production. Journal of Agrometeorology (special issue-part 1). Pp. 9-17.

Geethalakshami, V., Kokilavani, S, Nagarjan, R., Babu, C. and Poornima, S. (2008). Impact of climate change on rice and ascertaining adaptation opportunities for Tamil Nadu. Journal of Agrometeorology (special issue-part 2). Pp. 282-285.

Murthy, V.R.K. (2002). Basic Principles of Agricultural Meteorology; Book syndicate publishers, Koti, Hyderabad, India.

Rao, G.S.L.H.V.P and Subash, N. (1996). Use of CERES-Rice model to assess potential yield. International Rice Research Notes, 21(2/3): 87.

Tripathi. P, Tomer, S.K. and Singh, A.K. (1999). Crop weather models to predict the growth of rice and wheat under ricewheat cropping system, Published in proceeding of National Workshop of dynamic crop simulation modeling for Agrometeorological

Agro-advisory Services. Pp. 285-294.

\section{How to cite this article:}

Ashish Singh, A.K. Singh, A.N. Mishra and Singh, C.B. 2017. Yield Forecast of Rice Crop in Eastern U.P. Using Simulation Model. Int.J.Curr.Microbiol.App.Sci. 6(8): 1005-1009. doi: https://doi.org/10.20546/ijcmas.2017.608.124 